\title{
Legado da cultura alemã na literatura de Guimarães Rosa
}

\author{
German tradition heritage in Guimarães Rosa's literature
}

\section{Ivan Cláudio Pereira Siqueira ${ }^{1}$}

\begin{abstract}
João Guimarães Rosa was strongly influenced by the German literature, philosophy and music. The German tradition and its methods of associations suggested him to develop his own methodologies from the substrates provided by traditional Brazilian songs. This paper shows the general effects of musical techniques in short-stories of Sagarana, the influence of Heidegger's philosophy and the use of the concept of Wagner's Grundmotiv in "O burrinho pedrês" and "Sarapalha". Finally, it is proposed some connections between "A hora e vez de Augusto Matraga" (ROSA) and Parsifal, by Wagner.
\end{abstract}

Keywords: João Guimarães Rosa; Grundmotiv; Literature; Music; Wagner.

Resumo: A proximidade entre música, filosofia e literatura na tradição alemã e seus métodos de aproveitamento dessas relações marcou profundamente João Guimarães Rosa, possibilitandolhe desenvolver trilhas próprias a partir dos substratos oferecidos pelas cantigas tradicionais brasileiras. Os efeitos gerais das técnicas musicais em Sagarana, a influência de conceitos da filosofia de Heidegger, a utilização do Grundmotiv wagneriano em "O burrinho pedrês" e "Sarapalha" e as semelhanças entre a narrativa "A hora e vez de Augusto Matraga" e a ópera Parsifal, de Wagner, constituem o objeto desta reflexão.

Palavras-chave: João Guimarães Rosa; Grundmotiv; Literatura; Música; Wagner.

Zusammenfassung: Die Nähe zwischen Musik, Philosophie und Literatur in der deutschen Tradition und in ihren Methoden faszinierte João Guimarães Rosa zutiefst. Aus dem deutschen Beispiel heraus entwickelte er seine Methodenlehre der Organisation der brasilianischen traditionellen Lieder. Dieser Artikel diskutiert die allgemeine Wirkung der musikalischen Schreibtechniken in ausgewählten Kurzgeschichten aus dem Band Sagarana: In „O burrinho pedrês" und "Sarapalha“ wird der Einfluss von Heideggers Philosophie diskutiert bei gleichzeitiger Berücksichtigung vom Wagnerischen Konzept des Grundmotiven: In „A hora e a vez de Augusto Matraga“" werden die Beziehungen zu Wagners Parsifal analysiert.

Stichwörter: João Guimarães Rosa; Grundmotiv; Literatur; Musik; Wagner.

\footnotetext{
${ }^{1}$ Professor na ECA/USP, Doutor em Letras pela FFLCH/USP. Email: naviclauper@usp.br.
} 
Siqueira, I. - Legado a cultura alemã

\section{Filosofia e música alemãs na escrita rosiana}

O aproveitamento de traços culturais da tradição alemã constitui um dado singular ainda pouco estudado na obra de João Guimarães Rosa. Esse diálogo principia com a descoberta de que a sua cidade natal, Cordisburgo, trazia elementos germânicos nas reminiscências, na trajetória histórica e na etimologia, e se intensifica, entre outros, a partir da sua estada como cônsul-adjunto na Alemanha (1938-1942), e do aprimoramento na filosofia (Heidegger), na literatura (Goethe, Thomas Mann) e na música (Beethoven, Wagner). Essas sugestões aproveitam tópicos da tese de doutorado A música em Guimarães Rosa, trabalho que debate a obra de Rosa a partir de artifícios musicais (Grundmotiv) e suas correlações com a obra Parsifal, de Wagner, e com alguns conceitos filosóficos (Cf. SIQUEIRA 2009).

A aproximação ao universo cultural alemão pelo escritor mineiro se dá através de variadas formas, autores e épocas. Entretanto, pode-se iniciar por um conceito que lhe era precioso, a unicidade plural de mousikè, isto é, o emprego da palavra transfigurada em sonoridades, conceitos, etimologias e desvelamentos:

In der Einheit der altgriechischen Musikè trug das Wort den Rhythmus, möglicherweise sogar den Ton der gesanglichen Rezitation. Sprachliches und Musikalisches wirkten als Einheit auf den hörenden Menschen in (...) der miterlebenden Gemeinschaft durch die Katharsis der Tragödie (SCHIBLER 2000: 106).

Para Guimarães Rosa, a palavra não apenas cumpria a função de signo, na acepção de associação arbitrária de um conceito a uma imagem acústica (SAUSSURE 1978: 21). Mais do que isso, a sonoridade implicava no desvelamento de sentidos subterrâneos, muitas vezes obliterados na memória social. Daí a evocação dos significados implícitos em mousikè. Veja-se, por exemplo, algumas de suas criações: “A estória de Lélio e Lina", em que o nome do protagonista comunica, concomitantemente, o fogo, a energia solar (hélio) e a proximidade à companheira, pela sonoridade comum de seus nomes (Lélio/Lina); ou No Urubuquaquá, no Pinhém, cujo primeiro substantivo retoma a construção onomatopaica “qua-quá” para sugerir outras nuances na leitura da obra.

Buscando superar o prosaico, a palavra rosiana se articula a outras referências expressivas, valendo-se, em especial, de associações sonoras resultantes de processos de 
Siqueira, I. - Legado a cultura alemã

formação de palavras. Há vários exemplos de sua lavra assentados em métodos filológicos de evolução fonética da língua, como os metaplasmos aditivos: prótese (desfeliz), paragoge (noiteira), epêntese (costaneiros) e estrangeirismos (enjambar); supressão, aférese (“e”"stá), apócope (estranjas), síncope (cor"re"go), crase (quatrólhos), elisão (santiamén), haplologia (lusco-fusco); e modificação: diástole (seculórios), sístole (feitora) e eruditismo (sestros), (CoUTINHO, 1969: 166-188).

O extenso processo dessas manipulações linguísticas indica uma busca por efeitos musicais, conforme demonstram os seus cadernos de composição: "seu nome era uma dissonância inevitável”, "o rítmico uso da gradação", "modular - por reduplicação de situações e caracteres" (IEB/USP, CADERNO ESTUDOS PARA OBRA 4: 7, 8, 94). Por outro lado, o laboratório discursivo do ensaio dessas "dissonâncias" e "rítmicas gradativas" - as quais alcançaram o ponto máximo em Grande Sertão: Veredas - pode ser antevisto nas elaborações de uso da técnica do contraponto n“O burrinho pedrês”. O ritmo lento e cadenciado das descrições que margeiam o ritmo dos bois se contrasta com ritmo mais acelerado aludido pelos trens.

Algumas ideias-chave de Heidegger (GRANZ 2007) também parecem ter colaborado para o aperfeiçoamento da estética rosiana. Pode-se cotejar, por exemplo, a metáfora subjacente ao título Grande-Sertão: Veredas com os termos Lichtung, Aletheia e Erschlossenheit - as "veredas" constituiriam espaços privilegiados de desvelamento do ser, de aclaramento de verdades. Essas expressões remetem a um pensamento que se articula para além da herança ocidental dicotômica (sujeito/objeto), enfeixando a estética e a linguagem como elementos cruciais do arcabouço de proposições acerca do ser no mundo - questões essas que são centrais à literatura de Guimarães Rosa.

A prática comum de Heidegger de conceber neologismos (PALMER 1969) na língua alemã (ex: Dasein) ou de relevar outros significados em expressões já conhecidas (ex: Aletheia), na tentativa de entrelaçar o pensar, a natureza e o ser, tornou-se característica singular do estilo de Guimarães Rosa. Em Sagarana, "São Marcos”, o protagonista, tornado cego, orienta-se pela audição, no afã de estabelecer uma compreensão do ambiente no qual se encontra. Mais do que a razão, é a sensibilidade que o guia no esforço de encontrar possíveis caminhos para retornar aos conhecidos espaços de normalidade. Esse "caminho da floresta" percorrido pelo personagem é 
Siqueira, I. - Legado a cultura alemã

simultaneamente a reconstrução dos seus sentidos, a recuperação da sua percepção da realidade, ou seja, a sua Holzwege.

Paralelamente às sugestões filosóficas, Guimarães Rosa teve contato com a rica tradição alemã de intersecções entre literatura e música. Impressionou-o Die Meistersinger von Nürnberg (1868), Tannhäuser, (1845) Tristan und Isolde (1859); o protagonismo da música em Thomas Mann, que buscou mesclar forma musical e construções verbais, ora se utilizando do Trio op. 40, de Brahms, em Herr und Hund; Gesang vom Kindchen: Zwei Idyllen (1918), ora se apropriando do segundo movimento da sonata para piano, op. 111, de Beethoven, em Doktor Faustus (1947) (Cf. CARNEGY 1973).

Traços dessas influências na sua estética podem ser vislumbrados como a busca pela formalização de uma espécie de sinfonia existencial. Sinfonia que ora se aproximaria do estilo romântico tardio - a promoção de choques internos e abruptos, as modulações repentinas e o caminho para a desintegração da tonalidade (Wagner), em decorrência da incorporação crescente de ruídos que gradativamente enfraqueciam o domínio da tônica; ora do estilo clássico - a estabilidade formal favorecendo a atenuação dos contrastes, que eram integrados sob a órbita de pontes, transições e modulações (Haydn, Mozart e o primeiro Beethoven) (DAHLHAUs 1993). Essas alusões de atratividade e integração de tensões podem ter auxiliado Guimarães Rosa na sua intensa elaboração formal.

A fortuna crítica aqui utilizada para o paralelo entre a composição artística de Wagner e de Guimarães Rosa vale-se difusamente das óperas Tannhäuser (1845) e Tristan und Isolde (1859), focando-se especialmente na ópera Parsifal (1882), nas suas fontes, e nos escritos teóricos Oper und Drama (1852) e Religion und Kunst (1880), todos de Wagner. De Guimarães, o acervo do IEB/USP - cadernos de estudos do escritor e os demais textos das referências bibliográficas.

Oper und Drama é um texto de fôlego cujo primeiro título seria Wesen der Oper. À época, já próximo dos quarenta anos, o autor discorre sobre as suas principais inquietações em relação aos mecanismos e técnicas de composição da ópera, bem como sobre quais deveriam ser os caminhos para a escrita de uma obra absoluta Gesamtkunstwerk. No prefácio, a intenção da obra vem explícita: "Um mich verständlich zu machen, mußte ich auf die bezeichnendsten Erscheinungen unserer 
Siqueira, I. - Legado a cultura alemã

Kunst mit dem Finger hinweisen" (WAGNER 1852). Esse livro expressa as principais reflexões artísticas de Wagner, aprofundando questões apenas brevemente tratadas nos artigos Die Deutsche Oper (1834) e Über deutsches Musikwesen (1840).

Religion und Kunst é um ensaio longo, originalmente publicado como um número do periódico mensal Bayreuther Blätter (1878-1938), versando sobre as proximidades existentes entre religião e arte. Ao comparar a função da arte com o propósito das religiões, sobretudo a cristã, a budista e a judaica, Wagner, já perto do fim da vida, proclama a superioridade da obra de arte enquanto dimensão espiritual máxima da natureza humana - a arte como profissão de fé. O fragmento de um texto de Schiller, posto em versos como epígrafe do ensaio, corrobora o seu desencanto com o cristianismo:

\author{
Ich finde in der christlichen Religion \\ virtualiter die Anlage zu dem Höchsten \\ und Edelsten, und die verschiedenen \\ Erscheinungen derselben im Leben scheinen \\ mir bloss desswegen so widrig und abgeschmackt, \\ weil sie verfehlte Darstellungen dieses Höchsten sind (SCHILLER,1795).
}

Os escritos sobre o processo criativo de Guimarães Rosa, à disposição na biblioteca do escritor no IEB/USP, possibilitam entrever o seu grau de interesse pela utilização de recursos musicais na literatura. A série "Manuscritos" e os diversos cadernos de estudo apresentam diversos materiais que elucidam a genética composicional rosiana, assim como a inacabada narrativa $A$ fazedora de velas (Caderno 5: 9-10), que expõe a seguinte disposição musical:

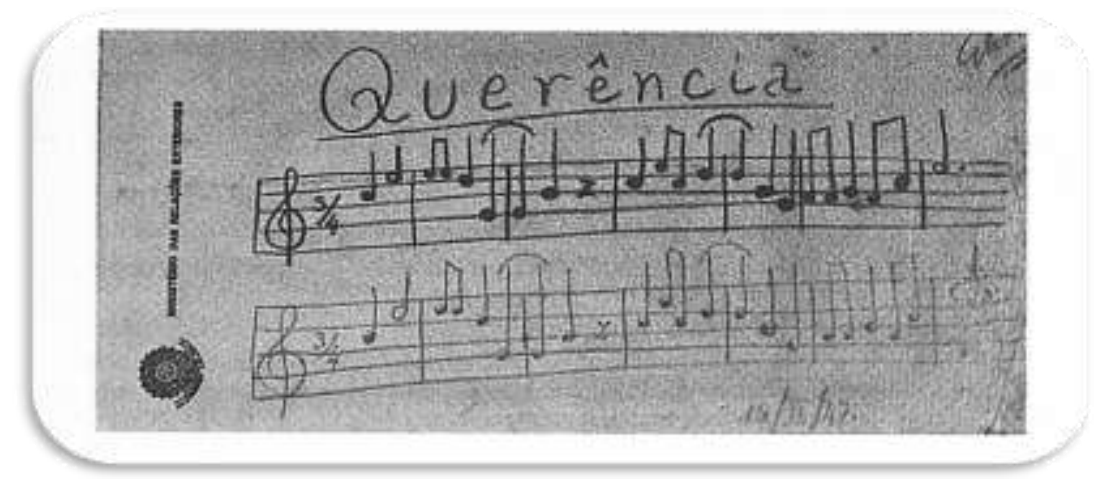

Pandaemonium, São Paulo, n. 17, Julho/2011, p. 239-258 - www.fflch.usp.br/dlm/alemao/pandaemoniumgermanicum 
Siqueira, I. - Legado a cultura alemã

\section{Grundmotiv sertanejo}

A conhecida expressão Leitmotiv (WOLZOGEN 1876) foi inspirada no Grundmotiv que Wagner teorizou em Oper und Drama (1852). Entretanto, há pormenores no conceito de Grundmotiv que diferem da noção geral de mera repetição de motivos:

Diese Einheit gibt sich dann in einem das ganze Kunstwerk durchziehende Gewebe von Grundthemen, welche sich ähnlich wie im Symphoniesatz, gegenüberstehen, ergängen, neu gestalten, trennen und verbinden [...]. Diese melodischen Momente, in denen wir uns der Ahnung erinnern, während sie uns die Erinnerung zur Ahnung machen, werden notwendig nur den wichtigsten Motiven des Dramas entblüht sein [...] (BROWN 1991: 48-9; 51-2).

O Grundmotiv wagneriano, mais do que apenas uma recorrência, compreendia a amálgama de Ahnung (antecipação), Erinnerung (reminiscência) e Vergegenwärtigung (atualização) numa Gebäude (organização de partes estruturadas). Esses sentidos integravam uma concepção que unia elementos dramáticos e musicais em suas óperas. Por meio da técnica do Grundmotiv, as peculiaridades sonoras, os desenhos rítmicomelódicos num dado componente dramático (personagem, passagem) ganhavam múltiplas conotações e possibilidades interpretativas (Cf. LORENZ 1922; 1966). A estratégia permitiu que Wagner se emancipasse de aspectos tradicionais (tema e desenvolvimento) da composição musical e da escrita operística (ária, recitativo, dueto), perseguindo a almejada Gesamtkunstwerk.

A partir de Sagarana, exemplos de Ahnung, de Erinnerung e de Vergegenwärtigung se multiplicam na obra de Guimarães Rosa, frequentemente na tentativa de constituir uma Gebäude de "tematizações musicais". Os pontos mais elevados dessa trajetória e a proeminência da música ocorrem em Corpo de Baile e Grande Sertão: Veredas, obras publicadas uma década após Sagarana (1946).

Numa determinada esfera da arquitetura artística, pode-se conjecturar que a narrativa rosiana é articulada consoante intermezzos que aproximam sonoridades, motivos e temas contrastantes. N“O burrinho pedrês”, o adjetivo aglutina cores (preto e branco), o animal macho é "rosado" (feminino), e está carregado (pesado) de algodão (leve). Por meio da cantiga, epígrafe da narrativa, a figuração da simbiose dos contrários 
se anuncia já na escolha do verbo "rodar" - indivíduo e mutirão se fundem num único conjunto:

E, ao meu macho rosado, carregado de algodão, preguntei: p'ra donde ia? P'ra rodar no mutirão (RosA 2001: 29).

Entretanto, a imagem viva de "rodar" possibilita conceber que em algum momento as informações díspares se deslocam, unindo-se ou se afastando. Há o uso de rimas consonantes /ã/ e toantes /a/ e /e/; de cesuras masculinas (meu, preguntei, rodar) e femininas (carregado). Predomina o equilíbrio entre as rimas internas /e/ e /a/. A distribuição das sílabas tônicas $(1,3,7)$, com a cesura na terceira, pontua o ritmo binário, sugerindo a cadência da movimentação dos bois.

O mesmo esquema rítmico em todos os versos ainda faculta o paralelo com o cotidiano da vida agreste. A conjunção adversativa que inicia a quadra "e" talvez tenha por função lembrar que existe qualquer coisa, alguma instância anterior (não revelada) que se liga ao contexto dado. A vírgula imprime uma pausa que contém o fluxo rítmico contínuo que aparentemente a conjunção evocaria. Diferente dessa pausa curta, os dois pontos se distinguiriam por acentuar um silêncio maior em "preguntei:”, marcando enfaticamente o que se segue "p'ra donde ia?". Aquela acenaria ao passado, esta ao futuro.

Reminiscências (Erinnerung) sonoras como "meu", "ma", índices de parentescos em "macho" e "mocho" e sílabas destacadas como "carre(gado)" e “(mu)tirão" parecem alentar a importância dos bois no texto.

A epígrafe é o primeiro Grundmotiv que modaliza a estrutura dos eventos: mocidade versus velhice (do burrinho e do Major Saulo); os desencontros da juventude do burrinho, comprado versus vendido, por bons versus maus preços; a complacência e resignação na velhice, com as pálpebras sempre em "semi-sono"; o "corpo decrépito" contrastando a brancura do "algodão bruto do pelo" com as "sementinhas escuras" sementinhas que espelham delicadeza em comparação ao pelo bruto; o algodão rivalizando com a escuridão das sementinhas. 
Siqueira, I. - Legado a cultura alemã

Os termos que iniciam o texto também instauram atmosfera ambígua: "era um burrinho pedrês" acena à fábula e ao pretérito imperfeito do indicativo; observando-se que o parágrafo seguinte começa pelo advérbio de tempo "agora", tem-se passado e presente.

A procedência do burrinho indica uma dualidade, ele é oriundo de "PassaTempo" (Conceição do Serro) ou de qualquer lugar do "sertão", isto é, de um local definido versus um indefinido - entretanto, tudo é sertão, o denominador comum. $\mathrm{O}$ período em que o burrinho se destaca irrompe das "seis da manhã à meia-noite", opostos fundamentais (manhã/início versus noite/fim) que resumem "um só dia de sua vida" (RosA, 2001: 30), o fenômeno da Gebäude wagneriana.

Há vários exemplos de antecipação (Ahnung): o abatimento de um bezerro por um jacaré antecipa a morte do menino Vadico pelo boi Calundú; a vaca traiçoeira que derruba os bois prenuncia a conduta ardilosa entre os vaqueiros, Silvino arquitetando contra Badú; e o estouro da boiada - narrado pelo personagem Manico antes do cruzamento de um "riozinho" - evocando a precipitação dos vaqueiros no córrego, tornado repentinamente rio volumoso. É a representação do passado se convertendo em presente, a ligação entre as gerações e os acontecimentos - conexão comparável à transição da tônica quando esta deixa de ser o centro da tonalidade para assumir o quarto grau e preparar a vinda de outro fundamento sonoro:

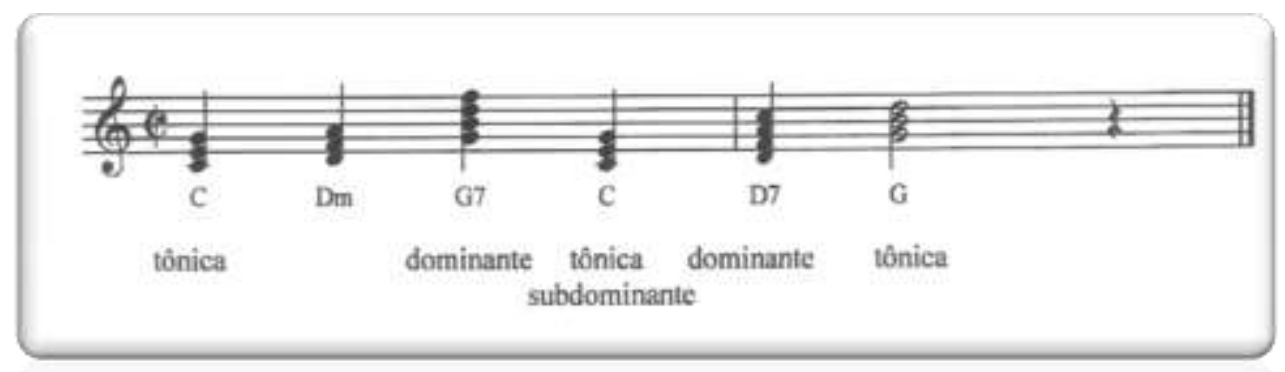

Em "Sarapalha", dois movimentos que perpassam a narrativa entrelaçam temas importantes da história. A malária "veio de longe, do São Francisco", fizera longa viagem, cada "ano avançava um punhado de léguas" (RosA 2001: 151), até se instalar no povoado e aniquilar os moradores. Sobraram os primos, que ainda não tinha morrido 
Siqueira, I. - Legado a cultura alemã

e nem ido embora. É que, para eles, tinha sido muito pior a fuga de Luísa com um boiadeiro que viera de terras distantes.

Essa oposição inicial que estrutura o relato (antes bons pastos, depois taperização) também se confirma nos antagonismos dos primos - Ribeiro, "fica sempre do lado do mato", "dorme mal" e sempre contraria Argemiro, que "fica sempre da banda do rio" e "não dorme quase nunca" (RosA 2001: 153-5). Note-se o contraponto entre "banda" (termo arcaico) e "lado" (termo moderno). Igualmente, a fuga da esposa do primo Ribeiro, Luísa, espelha um processo contrastivo - "foram pelo rio", diz Primo Ribeiro; não “foram de trem-de-ferro", replica Primo Argemiro (RosA 2001: 166).

O que une os primos, a inação, tem como contraposição a intensa na natureza:

\begin{abstract}
Aí a beldroega, em carreirinha indiscreta - ora-pro-nobis! ora-pro-nobis! - apontou caules ruivos no baixo das cercas das hortas, e, talo a talo, avançou. Mas o cabeça-deboi e o capim-mulambo, já donos da rua, tangeram-na de volta; e nem pôde recuar, a coitadinha rasteira, porque no quintal os joás estavam brigando com o espinho-agulha e com o gervão em flor. E, atrás da maria-preta e da vassourinha, vinham urgentes, do campo - oi-ái! - o amor-de-negro, com os tridentes das folhas, e fileiras completas, colunas espertas, do rijo assa-peixe (RoSA 2001: 152).
\end{abstract}

A descrição do combate das plantas é precedida pelo refrão em latim do verso da melodia gregoriana da "Ladainha à Ave Maria" - "ora-pro-nobis!" - "Sancta Maria, ora pro nobis/ Sancta Dei Genitrix, ora pro nobis [...]", uma canção fúnebre (RoSA 2001: 152). Trata-se de um cortejo, retrato das condições existenciais ali reinantes. Mas o féretro aí é uma metáfora para os humanos.

Com efeito, a agressividade das plantas, o firme propósito de lutar pela manutenção da vida sublinha a inépcia humana. A exteriorização do desânimo (malária) remete à desolação espiritual dos primos. A falta de coragem de Argemiro em se declarar à Luísa reforça a audácia do boiadeiro que a leva embora. O silêncio dos primos tem ainda o refluxo da sezão. É como se esses motivos contrastes conformassem um universo mais amplo de uma contaminação recíproca entre doença espiritual (amor), doença física (malária) e doença social (decadência institucional, de valores morais, econômica).

O princípio de oposição entre os primos expõe uma forma de conceber o episódio por meio de um desenvolvimento temático assemelhado ao uso wagneriano do Grundmotiv. Essas referências contornariam experiências significativas em pontos 
Siqueira, I. - Legado a cultura alemã

nevrálgicos da narrativa. Por exemplo, a chegada da malária, a ruína do arraial, a perda do patrimônio, da subsistência, a doença e a morte sofrem o influxo de uma corrente contrária - a fuga de Luísa, dos moradores e do único médico lá presente. Se para os que ficaram o resultado é a morte, para os que fugiram se supõe a oportunidade de uma vida nova.

Não se pode olvidar que a primeira versão do que posteriormente veio se denominar Sagarana (1946) tinha o título de Sezão (1937), inclusive era a primeira narrativa do livro, depois renomeada de "Sarapalha". Muitos dos seus fluxos ecoam pelos outros contos do livro - a decadência, a pobreza extrema, a fuga como último recurso de sobrevivência, a perda amorosa e a extensa atividade da flora, confrontandose com a inação humana.

O Grundmotiv wagneriano ainda pode ser visto em analogia ao termo "cocho". A hipótese é que a expressão implica uma ordenação de referências que se dissipam em várias direções da narrativa, inclusive, ultrapassando a esfera de ações dos episódios do conto. Assim, n“O burrinho pedrês" o termo encerra o seu sentido habitual: "E Badú caminhou e puxou o burrinho do cocho.” (RosA 2001: 77).

Em "Sarapalha" o vocábulo "cocho" é utilizado nove vezes (mesmo número de narrativas de Sagarana), mas não são os animais que vão ao seu entorno, são os primos Ribeiro e Argemiro. É o local que demarca as condições degradantes das personagens: "E tem também dois homens sentados, juntinhos, num casco de cocho emborcado, cabisbaixos, quentando-se ao sol" (RosA 2001: 153). O “cocho" é uma das imagens emblemáticas dos motivos arquitetados ao longo do texto, reverberando o rebaixamento das condições humanas das personagens, a passividade diante dos desafios, agravada pela comparação com a altivez das plantas. Por outro lado, é de se conjeturar certa contaminação entre as personagens e a natureza, pois até "A sombra do cedro vem se encostar ao cocho" (RosA 2001: 162).

O "coxo" é um elemento frequente no cenário dos parcos diálogos entre os primos. No clímax da narrativa, quando Argemiro confessa a primo Ribeiro que amava Luísa, outrora mulher de Ribeiro, e que sua ida ao lugarejo se prendia a esse pormenor: "E Primo Ribeiro, branco, encaveirado, soprando, e levantando o queixo a cada ofego, caiu sentado no casco de cocho outra vez" (Rosa 2001: 171), o "coxo" é o seu anteparo, ícone da deterioração. 


\section{Siqueira, I. - Legado a cultura alemã}

A cada aparição, o termo reforça o quadro de extenuação dos personagens, atualizando, paulatinamente, a decadência dos primos e da fazenda. $\mathrm{O}$ ressurgimento dessa palavra supõe associações e intercomunicações cumulativas ao seu campo semântico e aos demais motivos que a ela se ligam, produzindo tensão.

À medida que o discurso estabelece um mundo de exiguidades, aproximando o cenário de ruínas à renúncia dos personagens à vida, a imagem e a sonoridade de "cocho" estabelecem códigos intrínsecos que imprimem marcas por toda Sagarana: “cocho", "cachaça”, “cochilo". Essa paisagem de desolação no episódio é contraposta, antes até do seu início, por um fragmento de uma cantiga que já anteciparia as futuras dores e lamentações. Nesse mesmo espírito de arquitetura de oposições, fluxos e refluxos interligados, a cantiga ilumina um momento de dor, mas traz a ressalva de ser o trecho mais alegre:

Canta, canta, canarinho, ai, ai, ai...

Não cantes fora de hora, ai, ai, ai...

A barra do dia aí vem, ai, ai, ai...

Coitado de quem namora!...

( $\mathrm{O}$ trecho mais alegre, da cantiga mais alegre, de um capiau beira-rio.)

(Rosa 2001: 151).

\section{Parsifal e Matraga - a travessia do espírito}

Tornou-se clássica a recomendação (GALVÃo 1978) das três dimensões para a análise do protagonista de "A hora e vez de Augusto Matraga" - uma individual (Nhô Augusto), uma social (Augusto Esteves) e uma mítica (Matraga). Se empreendêssemos uma analogia com a forma sonata, obteríamos "exposição", "desenvolvimento" e "recapitulação". De fato, a viagem de Matraga em busca de si mesmo estabelece uma Durchführung (travessia), assim como a de Parsifal, por meio da qual os heróis logram a plenitude de sua existência.

Outro parentesco entre os personagens emerge quando Guimarães Rosa esclarece dúvidas sobre a sexualidade de Joãozinho Bem-Bem ao tradutor alemão: “Como se vê, o ponto é importante. Não se trata de não gostar de mulheres, ou falta de 
Siqueira, I. - Legado a cultura alemã

virilidade, como a tradução deixa supor. Ao contrário, o que o jagunço pretende é ser um Parsifal (...)” (RosA 1966).

Independentemente dessa menção do autor, a aspiração ao infinito e o dado mitológico são partilhados pelos dois personagens. O fato é que é perceptível o entusiasmo de Guimarães Rosa pela cultura alemã. São muitas as referências, algumas facilmente reconhecíveis, como a menção a Venusberg (I Ato de Tanhäuser, de Wagner) em “São Marcos” (Cf. RonCARI 2004).

A permeabilidade de pontos comuns entre Wagner e Rosa ainda pode ser verificada em seus cadernos de estudo no IEB, o que também já foi aventado por outros pesquisadores (Cf. SERRA 2006, BENEDETTI 2008: 249).

Para a composição do seu libreto (WAPNEWSKI 1978), Wagner teria se baseado nas versões de Parzival e o Titurel, de Wolfram von Eschenbach (1170-1220), e no Le Conte du Graal ou Le Roman de Perceval, de Chrétien de Troyes (1135-1183), além de se valer das lendas germânicas e de lições do budismo, entre outras possibilidades (OSTHOFF 1983).

A sua ópera Parsifal se passa em torno do Castelo de Monte Salvat ("tavlas", em turco - tábula, mesa), onde o rei Titurel mandara construir um castelo para receber o cálice e a lança. Seu principal cavaleiro é Gurnemanz. O rei passa a responsabilidade sagrada ao seu filho Amfortas. Mas Klingsor, querendo servir ao Graal, chega a se mutilar, por isso a sua castidade forjada não é aceita. Então ele jura vingança contra Amfortas. No caminho de Monte Salvat, ele manda erigir seu castelo com um jardim mágico, permeado de flores perfumadas e donzelas irresistíveis que enfeitiçam os cavaleiros. Tentando dar um basta à situação, Amfortas incursiona pelos domínios do rival, mas, seduzido por Kundry, perde a lança para Klingsor. A missão de Parsifal é recuperá-la e repor o estado de graça.

A primeira sugestão de aproximação entre Matraga e Parsifal é que ambos fazem uma viagem evolutiva, como muitos outros heróis, enfrentando grandes obstáculos para atingir a plenitude de si mesmo. Ainda generalistas são as três fases que os caracterizam, uma em que a vontade é quem domina (Nhô Augusto prepotente; Parsifal inconsequente), noutra, a reabilitação (o retiro de Nhô Augusto, a percepção de Parsifal de sua missão) e a última, em que a redenção advém pelo domínio da vontade (Matraga resistindo à violência gratuita; Parsifal resistindo a Kundry). 
Siqueira, I. - Legado a cultura alemã

Conforme a versão de Eschenbach, Parsifal vem do árabe "Fal-Parsi”, estúpido e inocente, carregando a ambiguidade no nome, pormenor análogo a Augusto Matraga. Como este, aquele tem vários nomes: "Ich hatte viele, doch weiss ich ihrer keinen $m e h r^{\prime 2}$. Nesse aspecto, a semelhança seria com Joãozinho Bem-Bem, que também desconhece a sua origem: "Sei lá de onde é que eu sou?!”, (Rosa, 2001: 393). Como Parsifal, ele pratica a continência sexual: "E as moças... Para mim não quero nenhuma, que mulher não me enfraquece", (RosA, 2001: 408).

$\mathrm{Na}$ ópera, o motivo musical que marca a passagem "Ich hatte viele, doch weiss ich ihrer keinen mehr" é pleno de uma sonoridade bastante tensa. A clave mostra a tonalidade de si bemol (Bb, C, D, Eb, F, G, A), mas o intenso cromatismo (D\#, E F\#, G\# e B\#) estabelece um contínuo deslocamento do que seriam os pontos de repouso, estilhaçando a tonalidade e sugerindo os desencontros da alma de Parsifal:

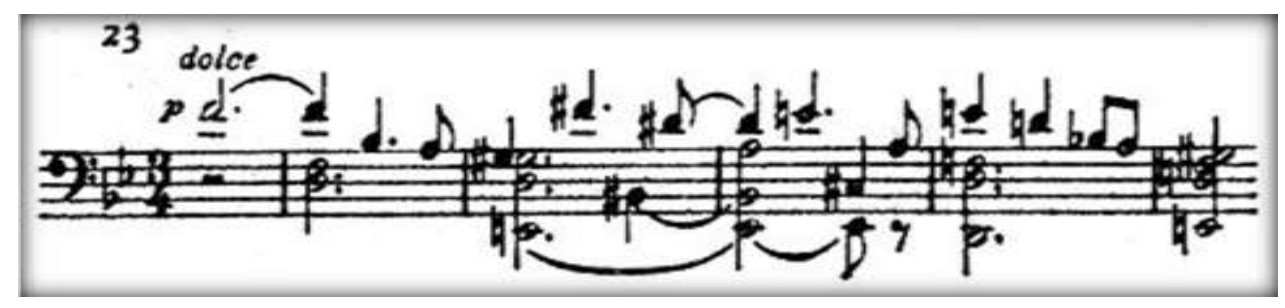

Ainda que por modos distintos, os dois enredos se apropriam de culturas alemã, celta, cristã, árabe e budista. A cena em que Nhô Augusto é encontrado por um negro velho, num certo aspecto, lembra aquela em que Gurnemanz acolhe Kundry: "Mas o preto que morava na boca do brejo, quando calculou que os outros já teriam ido embora, saiu do seu esconso, entre as taboas, e subiu os degraus de mato do pé do barranco" (RosA 2001: 376). No texto da ópera:

Im Vordergrunde, an der Waldseite, ein Quell; ihm gegenüber, etwas tiefer, eine schlichte Einsiedlerhüte, an einen Felsblock gelehnt. Frühester Morgen. Gurnemanz, zum hohen Greise gealtert, als Einsiedler, nur in das Hemd der Gralsritter gekleidet, tritt aus der Hütte und lausch (WAGNER 1882: PARSIFAL, III ATO).

\footnotetext{
${ }^{2}$ Frase de Parsifal acompanhada de motivo musical - "Ich hatte viele, doch weiss ich ihrer keinen mehr": http://www.rwagner.net/libretti/parsifal (22/04/2011).
} 
Siqueira, I. - Legado a cultura alemã

O que chama atenção é que ambos os acolhedores estão em uma situação de total despojamento, longe do convívio social. Matraga e Parsifal são recebidos por dois velhos que vivem em situação de extrema simplicidade, em contato profundo com a natureza. Possivelmente, isso redunde em certo grau de pureza de sentimentos, em contraste com outros personagens.

Outra proximidade ocorreria na passagem em que os finais apresentam resoluções opostas, apesar de inicialmente análogos. Na ópera, quando um cisne é ferido, Gurnemanz pergunta a Parsifal: “Wer schoss den Schwan?”. Parsifal diz que o pássaro havia sido morto por ele. O diálogo é acompanhado de uma orquestração incisiva, que ilumina a ação da personagem. Já Nhô Augusto age de modo diferente, pois está num outro momento. Ao se encontrar com Joãozinho Bem-Bem, este aconselha: “- Pode gastar as oito. Experimenta naquele pássaro ali, na pitangueira...”. Ao que Nhô Augusto retruca: “- Deixa a criaçãozinha de Deus. Vou ver só se corto o galho..." (RosA 2001: 395). Como Nhô Augusto vivencia o período de "recapitulação" dos seus atos, ele recusa a oferta, mas a cena talvez aponte para a semelhança da falta de motivação para a violência em determinadas circunstâncias.

Desde o primeiro instante em que o vê, Joãozinho Bem-Bem se afeiçoa a Matraga: "E Flosino Capeta pasmou deveras, porque era a coisa mais custosa deste mundo seu Joãozinho Bem-Bem se agradar de alguém ao primeiro olhar" (RosA 2001: 390). Também Gurnemanz imediatamente pressente alguma distinção em Parsifal: "Doch adelig scheinst du selbst und hochgeboren" (WAGNER 1882: Parsifal, III Ato).

A ideia de fusão entre personagem, travessia e tempo parece literal a Parsifal quando Gurnemanz diz a ele: "Du siehst, mein Sohn, zum Raum wird hier die Zeit" (WAGNER Ibid).

De certo modo, os vícios cardinais budistas que ambos os heróis devem superar em suas travessias espirituais se assemelham, bem como a aceitação da virtude oposta: a volúpia abandonada em prol da castidade (Nhô Augusto desrespeitador até de mulheres casadas, Parsifal seduzido por Kundry); a violência gratuita (Parsifal fere o pássaro desnecessariamente, Nhô Augusto agride o capiau da Sariema) pela generosidade (Parsifal se compadece do suplício de Amfortas, Nhô Augusto enfrenta Bem-Bem para salvar uma família); e a ira pela brandura (Nhô Augusto incontível, com o diabo no corpo, depois ameno, lavrando a terra e cuidando do povoado). 
Siqueira, I. - Legado a cultura alemã

A função de Joãozinho Bem-Bem de personificar o alterego de Matraga e, pela mesma razão, de ser a sua principal fonte de tentação - "se o senhor quisesse vir comigo", "e seus dedos tremiam, porque essa estava sendo a maior das suas tentações" (RosA 2001: 407) -, quiça corresponda ao papel de Kundry. Ela serve tanto ao Graal quanto a Klingsor, quando é por ele enfeitiçada. Não obstante ser o meio pelo qual Parsifal se cura de si mesmo (tolo inocente), ela é curada por obra dele, possivelmente como no combate derradeiro em que Joãozinho Bem-Bem é salvo de cometer atrocidades graças à bravura de Matraga.

Comparativamente à negativa de Nhô Augusto ao chamado das armas por Joãozinho Bem-Bem, o que confirma sua superação, Parsifal só se reinventa na pele do salvador quando resiste às tentações do beijo de Kundry.

É às voltas com essa revelação que ele se comove profundamente com o sofrimento de Amfortas, que padecia de um ferimento horrível após o incidente com a lança sagrada. Então ele vislumbra o universo de dores e misérias infindas que é a vida. Compaixão e renúncia (KIENZLE 1992) eram as armas para sublevar a imensa dor causada pela vontade impetuosa e a cegueira, sua acompanhante. A violência excessiva, responsável pelo declínio de Matraga, é a arma que promove a sua "hora e vez", quando administrada pela indulgência.

Uma questão decisiva (JUNG \& FRANZ 1998), tida como enigmática do seu motivo central que se reitera constantemente perpassa o Graal. Na versão de Troyes, o herói pergunta "Quem serve o Graal?"; na de Eschenbach, "Senhor, por que sofres tanto?" (dirigida a Amfortas); na de Wagner, “Quem é o Graal?”. Em “A hora e vez de Augusto Matraga" uma das questões centrais, verdadeira obsessão, é a sua "hora e vez". Naturalmente, cada uma delas tem foco, tempo e universo específicos. Troyes se utiliza de culturas gaulesas; Eschenbach acentua a origem cristã do Graal; Wagner está preocupado com a arte e as possibilidades oferecidas pelo mito, nisso Guimarães Rosa não difere dele.

Em Wagner, Kundry é ambígua, transitando entre os reinos de Klingsor (magia, orgia) e do Graal (mistério, silêncio, castidade). Na sua ópera, o drama do Graal não é compreendido por Parsifal até que ele o reviva de forma dramatizada através da ruptura entre sensibilidade e inteligência (LÉVI-STRAUSS 1975). Se Eschenbach reposiciona as 
Siqueira, I. - Legado a cultura alemã

suas origens cristãs, Wagner vai além, admitindo várias outras fontes religiosas e místicas, visto que o seu interesse era, sobretudo, a arte.

Wagner e Guimarães Rosa se valeram de arquétipos e inúmeras lendas, buscando approaches singulares, cada um a seu modo, e com os recursos históricos de que dispunham para retratar travessias transcendentais operadas pela arte. Com efeito, a síntese do conceito operístico exposto em Oper und Drama (WAGNER 1852) também poderia ser tomada como o colorário da estética rosiana:

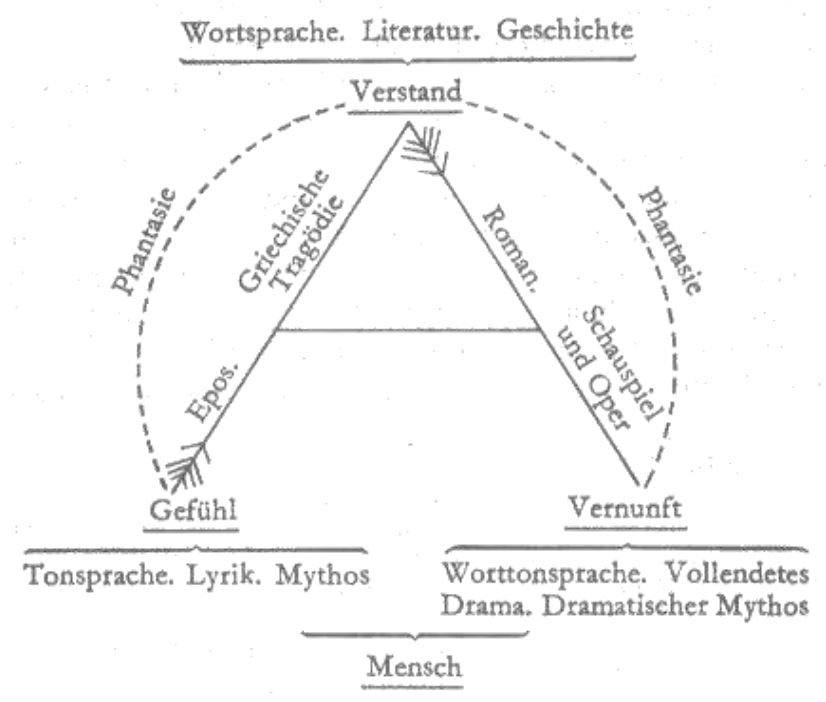

A imagem parece similar à descrição do triângulo e da circunferência - marcas da predestinação de Matraga. A figura foi elaborada pelo próprio artista (WAGNER, ibid.). Os pormenores dos conceitos são curiosos: no topo da ilustração se lê Linguagem Oral, Literatura e História, que têm como base o Entendimento. Este, pelo lado esquerdo, através da Imaginação, se liga ao Sentimento, cujo fundamento está na Melodia da Língua, no Lirismo e no Mito; do Sentimento ascendem a Epopeia e a Tragédia Grega, que conectam o Sentimento ao Entendimento; pela direita, do Entendimento, também por meio da Imaginação, descendem a Narrativa, o Teatro e a Ópera, cujo alicerce é a Razão, apoiada no Discurso Tonal, no Drama e no Mito Dramatizado. Todo esse universo tem o Homem como mentor.

Excetuando-se as preocupações com o teatro, a ópera e algumas especificidades tonais, a síntese que Wagner elabora do seu projeto de arte total, no qual Parsifal tem 
Siqueira, I. - Legado a cultura alemã

um papel relevante, contém praticamente a essencialidade das considerações apontadas pela crítica na obra de Guimarães Rosa: a oralidade e melodia da língua, as relações entre literatura, filosofia e história, a fantasia e o sentimento, o lirismo, a mitologia e o diálogo com a cultura greco-romana.

Nesse sentido, é interessante a assertiva de Wagner, Religion und Kunst (1880) sobre o papel da arte e da religião, vistas a partir do conturbado contexto do século XIX, o qual provavelmente também delineia pontos de contato com a visão de Guimarães Rosa sobre a referida temática religiosa em "A hora e vez de Augusto Matraga":

One might say that where Religion becomes artificial, it is reserved for Art to save the spirit of religion by recognising the figurative value of the mythic symbols which the former would have us believe in their literal sense, and revealing their deep and hidden truth through an ideal presentation. Whilst the priest stakes everything on the religious allegories being accepted as matters of fact, the artist has no concern at all with such a thing, since he freely and openly gives out his work as his own invention. (WAGNER 1897: 213)

Ao mesmo tempo em que Parsifal e "A hora e vez de Augusto Matraga" se utilizam de extratos do cânone cristão, há a incorporação seletiva de misticismos e mitologias mais antigas, como os Eddas - The Elder Eddas (Saemund Sigfusson) e Younger Eddas (Snorre Sturleson), fontes especialmente relevantes para a literatura germânica e nórdica de meados do século XIX (MATTOS 1959). Contrapondo-se ao ethos religioso do cristianismo da ascese por fases, da transladação de uma esfera natural a uma sobrenatural, a função da magia é promover a fusão e a indistinção de ambas, como ocorre nas duas estéticas.

Daí a ambiguidade de Kundry, de ser simultaneamente o bem e o mal, assim como Joãozinho Bem-Bem, que, acreditando praticar a justiça opera terríveis desfechos: “Gente minha só mata as mortes que eu mando, e morte que eu mando é só morte legal!” (RosA 2001: 392). Além dessas aproximações mais ligadas ao enredo, restaria considerar alguns aspectos musicais.

Wagner elabora melodias transfiguradas por cromatismos que buscam alargar o universo tonal. A expansão da ambientação sonora pelo dilatamento do diatonismo e o idealismo que converge para dentro da realidade dos personagens empreendem a sua busca pela Gesamtkunstwerk. As descontinuidades sonoras demarcam os limites das 
Siqueira, I. - Legado a cultura alemã

passagens no episódio, as cenas mais importantes se elevam pela gradação numa articulação de eventos que assinalam mudanças significativas.

Em consequência, é um motivo musical a desvelar que, assim como Parsifal é o responsável pela morte de sua mãe (ela morre desconsolada após a sua partida), Amfortas o é pela de seu pai (a perda do Graal para Klingsor). Constantemente, os momentos decisivos do enredo são tensionados por correspondências musicais: "The symbolic substitutions in the spiritual drama interact with transformational substitutions in the tonal realm" (LEWIN 2006: 183).

A linguagem própria do drama interage e se transforma constantemente pela alteração dramática do Grundmotiv na música. Daí as frequentes modulações que impõem a conversão do modo menor em maior, e vice-versa, a ponto de não se perceber mais a distinção. São conhecidas as passagens harmônicas wagnerianas que primam pela ambiguidade sonora, como as polaridades das progressões hexatônicas, que destituem o centro tonal do senso de gravitação, uma das quais é a célebre cena em que a alma de Kundry abandona o seu corpo (BROWER 2008: 58):

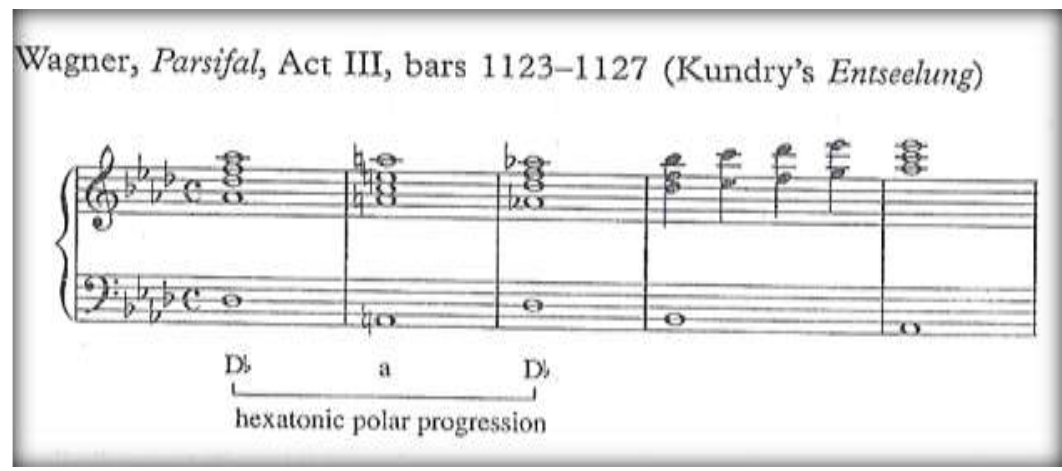

Esse intercâmbio permanente entre texto e música não ocorre de modo também significativo na história de Matraga? Assim como as modulações musicais se integram indissociavelmente ao libreto de Parsifal, as cantigas e outras alusões sonoras não seriam incorporadas aos acontecimentos nevrálgicos de "A hora e vez de Augusto Matraga"? A travessia de Matraga, ao ser redimensionada por outros arcos de significação, dirige-se à almejada transcendência universal (LINS, 1963: 260-263), amparada pela saga germânica. 
Siqueira, I. - Legado a cultura alemã

Como sujeito e objeto, antecedente e consequente, dissonâncias e consonâncias tonais, finalmente, depois de sua Durchführung, Augusto Matraga encontra o seu repouso, a sua "hora e vez", em sintonia com "a hora e vez" de Joãozinho Bem-Bem e Parsifal. A sinfonia está completa.

\section{Referências bibliográficas}

BENEDETTI, Nildo. Sagarana: o Brasil de Guimarães Rosa. Tese de Doutorado. FFLCH/USP, São Paulo, 2008, 249.

Brower, Candace. Paradoxes of Pitch Space. In: Musical Analysis, 27 (1), mar. WileyBlackwell. Oxford/USA, 2008, 58.

Brown, Hilda. Oper und Drama. In: Leitmotiv and Drama: Wagner, Brecht, and the limits of Epic Theatre. Oxford, Clarendon Press, 1991, 48-9, 51-2.

CARnegy, Patrick. Faust as Musician: A Study of Thomas Mann's Novel 'Doktor Faustus'. New York, New Directions Press, 1973.

CoutınHo, Afrânio. Guimarães Rosa. Rio de Janeiro, Civilização Brasileira, 1991, 83.

Coutinho, Ismael. Gramática Histórica. $6^{\text {a }}$ ed. Rio de Janeiro, Livraria Acadêmica, 1969, 166188.

DAHLHAUS, Carl. Ludwig van Beethoven: approaches to his music. Oxford, Oxford University Press, 1993.

EsCHENBACH, Wolfram von. Parzival. Trad. A.T. Hatto. Harmondsworth, Penguin Books, 1980.

GALVÃo, Walnice. Matraga: sua marca. In: Mitologia rosiana. São Paulo, Ática, 1978.

GRANZ, Holger. Die Metapher des Daseins - Das Dasein der Metapher. Eine Untersuchung zur Metaphorik Heideggers. Frankfurt am Main, Peter Lang Verlag, 2007.

InwooD, Michael. A Hegel Dictionary. Oxford, Blackwell Publishers, 1992.

Jung, Emma; Franz, Marie-Louise von. The Grail Legend. Trad. Andrea Dykes. Princeton, University Press, 1998.

KIENZLE, Ulrike. Das Weltüberwindungswerk: Wagners Parsifal: ein szenisch-musikalisches Gleichnis der Philosophie Arthur Schopenhauers. Laaber-Verlag, 1992.

LeVI-STRauss, Claude. De Chrétien de Troyes à Richard Wagner. In: Parsifal, Programmhefte der Bayreuther Festspiele, 1975. Reproduzido in Le Regard Éloignée. Paris, Plon, 1983, 301-318.

LEWIN, David. Amfortas's Prayer to Tituriel and the Role of D in Parsifal: The Tonal Spaces of the Drama and the Enharmonic Cb/B. In: Studies in Music with Text. Oxford, Oxford University Press, 2006, 183.

LinS, Álvaro. Sagas de Minas Gerais. In: Os Mortos de Sobrecasaca, Rio de Janeiro, Civilização Brasileira, 1963, 260-263.

LORENZ, Alfred. Das Formproblem in Richard Wagner's Musik. Munique, 1922.

LoRENZ, Alfred. Das Geheimnis der Form bei Richard Wagner. 4 vol. Berlin, Hans Schneider, 1966 (Reimp). 
Siqueira, I. - Legado a cultura alemã

MatTos, Sônia. Deuses e heróis na Edda poética e na Tetralogia de Wagner. Tese de Livredocência, FFLCH/USP, São Paulo, 1959.

OsthofF, Wolfgang. Richard Wagners Buddha-Projekt Die Sieger: Seine ideellen und strukturellen Spuren in Ring und Parsifal. Arkiv für Musikwissenschaft 40 (3), 1983, 189-211.

PALMER, Richard. Hermeneutic: Interpretation Theory in Schleiermacher, Dilthey, Heidegger, and Gadamer. Evanston, Northwestern University Press, 1969.

RONCARI, Luiz. O Brasil de Rosa: mito e história no universo rosiano: o amor e o poder. São Paulo, Unesp, 2004.

RosA, Guimarães. Sagarana. Rio de Janeiro, Nova Fronteira, 2001.

RosA, Guimarães. Carta de 11 de outubro de 1966 a Curt Meyer-Clason. Acervo IEB-USP.

SAUSSURE, Ferdinand de. Curso de Linguística Geral. São Paulo, Cultrix, 1978, 21.

SCHIBLER, Armin. Grundsätzliches zur Suche nach einer neuen Sinngebung der Musik 5. In: SCHIBLER, Gina. Wenn das Tönende die Spur der Wahrheit ist ... Das Werk des Komponisten und Musikdramatikers Armin Schibler in seiner Bedeutung für die Gegenwart. Bern, Peter Lang-Verlag, 2000, 106.

SERRA, Tania. A travessia de 'Riobaldo Rosa', no Grande Sertão: Veredas, como um processo de individuação. In: Aletheia, (24), jul/dez, 2006, 69-80.

SIQUEIRA, Ivan. A música na prosa de Guimarães Rosa. Tese de Doutorado. FFLCH/ USP, São Paulo, 2009.

Troyes, Chrétien de. Le conte du Graal ou le Roman de Perceval. Paris, Librairie Générale Française, 1994.

WAGNER, Richard. Oper und Drama. Trad. Willian Ashton Ellis. London: The Wagner Library, 1893: 16. http://users.belgacom.net/wagnerlibrary/prose (22/04/2011).

WAGNER, Richard. Religion und Kunst. Trad. Willian Ashton Ellis. London, The Wagner Library, 1897, 213. http://users.belgacom.net/wagnerlibrary/prose (22/04/2011).

WALZEL, Oskar. Gehalt und Gestalt im Kunstwerk des Dichters. In: Handbuch der Literaturwissenschaft, 1923/4.

WAPNEWSKI, Peter. Parzival und Parsifal oder Wolframs Held und Wagners Erlöser. In: Richard Wagner: von der Oper zum Musikdrama. München, S. Kunze, 1978, 47-60.

Wolzogen, Hans von. Thematischer Leitfaden durch die Musik zu Rich. Wagners Festspiel 'Der Ring des Nibelungen'. Leipzig, Schloemp, (1ª ed.1876), 1988 (Reimp).

Recebido em07/10/2010

Aprovado em 20/03/2011

Pandaemonium, São Paulo, n. 17, Julho/2011, p. 239-258 - www.fflch.usp.br/dlm/alemao/pandaemoniumgermanicum 